\title{
O mediador e a mediação de literatura para crianças surdas
}

\author{
The Mediator and the Mediation of the Literature for deaf child
}

\author{
Ana Paula Pereira \\ Graduada em Biblioteconomia pela Universidade Estadual de Londrina - UEL. \\ E-mail: appuel@yahoo.com.br
}

\begin{abstract}
Sueli Bortolin
Doutora em Ciência da Informação pelo Programa de Pós-Graduação em Ciência da Informação da

Universidade Estadual Paulista 'Julio de Mesquita Filho', campus de Marília. Pofessora do Departamento de Ciência da Informação da Universidade Estadual de Londrina - UEL.

E-mail: bortolin@uel.br
\end{abstract}

\section{Resumo}

Discute a mediação da leitura e da literatura infantil como fator de inclusão e de acessibilidade para as crianças surdas. Aborda como a mediação pode contribuir na valorização da autonomia e dignidade das crianças surdas. Destaca o papel do mediador de leitura como facilitador da relação entre o leitor e o texto, salientando que ler é um direito de todos. Elenca as possibilidades da literatura infantil, da descoberta dos significados a partir do olhar, das percepções e experiências do leitor. Afirma que a mediação com livros de imagem pode propiciar o interesse e o gosto pelos livros e pela literatura. Por intermédio de um estudo de campo e da entrevista gerativa de narrativa objetivou-se evidenciar a mediação por meio de livros de imagem como incentivo à leitura para crianças surdas, além de mencionar as dificuldades que as crianças surdas enfrentam no universo da leitura; identificar as atividades que propiciam a apropriação da leitura pelas crianças surdas; elencar as estratégias e habilidades do mediador para propiciar a leitura para as crianças surdas e apresentar os livros de imagem como possibilidade de mediação para as crianças surdas. Parte do princípio de que os mediadores enfrentam dificuldades na inserção das crianças surdas no universo da leitura e de que o livro de imagem seria uma possibilidade de superá-las. Enfatiza que a responsabilidade do mediador em favorecer o desenvolvimento das crianças surdas de maneira crítica, consciente e ética é possível e, também, necessária. Conclui que a mediação com livros de imagem pode se constituir em ação de incentivo à leitura para crianças surdas.

Palavras-chave: Mediação da Leitura. Mediação da Literatura. Crianças surdas. Livro de imagem.

\begin{abstract}
Discusses the mediation of reading and children's literature as fator as inclusion and accessibility for deaf children. It discusses how mediation can contribute to the enhancement of the autonomy and dignity of deaf children. Highlights the reading mediator's role as facilitator of the relationship between the reader and the text, pointing out that reading is a right for all. It lists the possibilities of children's literature, the discovery of meanings from the look, the perceptions and experiences of the reader. States that mediation with picture books can provide interest and love for books and literature. Through a field study and generative interview of narrative aimed to highlight the mediation through picture books to encourage reading for deaf children, and mention the difficulties that deaf children face in the reading of the universe; identify the activities that promote the reading of ownership by deaf children; list the strategies and mediating skills to provide reading for deaf children and submit the picture books as possibility of mediation for deaf children. It breaks of the beginning that the mediators face difficulties in the deaf children's insert in the universe of the reading and that the image book would be a possibility to overcome them. Stresses that the responsibility of the mediator to encourage the development of deaf children critically conscious and ethics is possible and also necessary. It concludes that mediation with picture books may constitute action to encourage reading for deaf children.
\end{abstract}

Keywords: Mediation of the Reading. Mediation of the Literature. Deaf children. Image book.

Bibl. Esc. em R., Ribeirão Preto, v. 5, n. 1, p. 83-104, 2016.

DOI: 10.11606/issn.2238-5894.berev.2016.112384 


\section{Introdução}

A leitura é fator básico e fundamental para o desenvolvimento da sociedade, pois em geral, ler torna os indivíduos mais críticos. Por isso, conhecer o conceito de mediação da leitura é importante para entender em que medida este ato efetuado pelo mediador leva o indivíduo a leitura, principalmente as crianças surdas.

Entendemos também que a ação de mediação está vinculada a maneira como o mediador utiliza ou desenvolve estratégias e habilidades específicas com os seus leitores alterando sua prática cotidiana. Assim, é por meio da mediação que o mediador pode despertar o interesse pela leitura, levando o leitor ao melhor encontro possível com os textos.

Acreditamos que o livro de imagem não se destina somente as crianças não alfabetizadas pelo fato de não conter palavras. Ao contrário, é uma leitura complexa que adultos podem ter dificuldade porque requer envolvimento, baseado nas experiências do leitor, nas suas indagações perante as imagens, dos sentidos que ele atribui e das relações que faz. Relações que a mediação da literatura pode provocar.

A partir deste contexto, o estabelecido para esta investigação foi evidenciar a mediação por meio de livros de imagem como incentivo à leitura para as crianças surdas. Pretendemos evidenciar que o mediador precisa conhecer as dificuldades que a criança surda enfrenta no ato de ler. Quanto aos objetivos específicos arrolamos: a) Mencionar as dificuldades que as crianças surdas enfrentam no universo da leitura; b) Identificar as atividades que propiciam a apropriação da leitura pelas crianças surdas; c) Elencar as estratégias e habilidades do mediador para propiciar a leitura para as crianças surdas; d) Apresentar os livros de imagem como possibilidade de mediação para as crianças surdas.

Tivemos também a intenção de abordar os conceitos de mediação, conhecer estratégias de mediação e suas relações com as crianças surdas, bem como propor a leitura do livro de imagem como alternativa cativante que pode contribuir para o seu desenvolvimento ao provocar o encontro com a literatura e com a leitura.

$\mathrm{Na}$ sociedade atual o acesso à leitura é essencial, pois é o elemento que permite a formação e a criticidade dos indivíduos. Além disso, no caso das crianças surdas contribui para a sua condição de igualdade, isto é, minimiza sua exclusão. No entanto, para elas esse acesso é 
mais difícil devido às condições desiguais de acessibilidade aos bens culturais, consequentemente a ausência dos diferentes gêneros de mediação.

Nesse sentido, deve-se possibilitar a acessibilidade plena e não parcialmente, especialmente nas escolas e nas bibliotecas que são espaços em que cultura, sociedade e informação estão interligadas e têm nos mediadores a possibilidade de dominar a leitura e a literatura a partir da mediação.

A presença da biblioteca é de suma importância uma vez que a democratização do acesso à leitura é sua função principal. Assim, a acessibilidade e a mediação adequada precisam ser a preocupação primordial dessa instituição. Aliás, estes são fatores que efetivam o "encontro" com a literatura. Para isso, é fundamental conhecer as reais necessidades de seus leitores para assim buscar as habilidades para atendê-las.

Diante dessa realidade, as escolas e as bibliotecas podem promover políticas de acessibilidade à leitura, especialmente com a mediação da leitura, como garantia de direitos, da democracia e da cidadania.

Portanto, é preciso despertar nas crianças surdas o interesse pela leitura por meio da mediação. Faz-se necessário a união de acessibilidade, mediação, estratégias e habilidades do mediador a fim de formar leitores e para que a leitura esteja ao seu alcance. Dessa forma, nos deparamos com o seguinte problema: de que maneira a mediação com livros de imagem constitui-se como ação de incentivo à leitura para crianças surdas?

Diante da questão da mediação como ação de incentivo à leitura para crianças surdas, justificamos nosso estudo a partir da realidade, onde há um número significativo de crianças surdas que necessitam da mediação e do mediador para desenvolver o ato da leitura e ampliar o contato com a literatura, em uma escola especializada.

As crianças surdas precisam de uma mediação adequada, isto é, uma ação capaz de incluí-las de maneira prazerosa no universo da leitura. Para isso, a ação do mediador é fundamental a fim de promover e incentivar o ato de ler ao mesmo tempo em que se respeita e se atende às necessidades de tais leitores.

Outra justificativa é a possibilidade de demonstrar que a ação do mediador é contribuir para a inclusão das crianças surdas nas bibliotecas, além de fornecer os elementos essenciais à formação de leitores a partir da mediação inclusiva, aliada ao uso da Língua Brasileira de Sinais 
(LIBRAS) que é uma ferramenta de aproximação e diálogo que o mediador pode utilizar durante suas atividades.

Procuramos identificar se a atividade de mediação propicia a apropriação da leitura pelas crianças surdas, evidenciando que os livros de imagem são dispositivos de mediação significativos para elas.

A elaboração desta pesquisa pode corroborar diretamente a uma temática ainda em desenvolvimento, pois o enfoque abordado pode se constituir como um componente de mudanças nas ações de mediação e de reflexão, tanto para profissionais da informação quanto para outros profissionais. Assim, podemos contribuir para o avanço da Biblioteconomia ao fornecer um estudo que analisa a mediação da leitura como fator de acessibilidade e de garantia às crianças surdas, de seus direitos, dentre os quais a leitura e a literatura são primordiais.

Dessa forma, este trabalho constitui-se das seguintes subseções: marco teórico (a mediação da leitura para crianças surdas), procedimentos metodológicos, apresentação dos resultados e considerações finais.

\section{Mediação da Leitura para crianças surdas}

O gênero de mediação abordado nesse trabalho é a da leitura. Esse tema vem sendo substancialmente explorado nas áreas de Educação e Letras, mas aos poucos tem marcado presença também na Ciência da Informação. Aqui, especificamente, abordamos a mediação da leitura literária para as crianças surdas. O que é leitura literária? Mediação da leitura literária é segundo Bortolin (2010, p. 115) “[...] a interferência casual ou planejada visando a levar o leitor a ler literatura em diferentes suportes e linguagens".

$\mathrm{O}$ ato de mediação é tão fundamental na vida do leitor que deveria ser realizada diuturnamente pelos mais diferentes mediadores, sendo eles familiares, profissionais, voluntários; gente comum, atores. Para tanto essas pessoas

[...] devem realizar leituras, fazer pesquisas, buscar subsídios no sentido de aprender os diferentes significados de leitura, conhecer as múltiplas linguagens, analisar textos de diferentes gêneros, entender as fases psicológicas dos leitores e também descobrir como acontece a recepção de um texto por parte do leitor (seja lendo ou ouvindo). (BORTOLIN, 2010, p. 83).

Quando a mediação é realizada com crianças especiais, toma uma dimensão mais complexa, nessa pesquisa o foco é nas “crianças surdas”, vale esclarecer que a utilização desse 
termo se deu pelo fato de que a comunidade surda, ao contrário do que se divulga preconiza o uso da palavra surdo com naturalidade. Gesser (2009, p. 45) explica que

\begin{abstract}
A maioria dos ouvintes desconhece a carga semântica que os termos mudo, surdomudo e deficiente auditivo evocam. É facilmente observável que para muitos ouvintes alheios à discussão sobre surdez, o uso da palavra surdo pareça imprimir mais preconceito, enquanto o termo deficiente auditivo parece-lhes ser mais politicamente correto.
\end{abstract}

O autor ainda destaca o posicionamento de uma professora surda: “[...] Eu sou contra o termo surdo-mudo e deficiente auditivo porque tem preconceito... Vocês sabem quem inventou o termo deficiente auditivo? Os médicos [...]" (GESSER, 2009, p. 45). Desse modo, o termo deficiente auditivo tem origem na Medicina e embora pareça ser mais adequado, também remete ao preconceito.

Eis a razão do termo surdo em nosso trabalho. Vale ressaltar que "não é apenas a escolha acertada de um termo que elimina os preconceitos sociais. Os preconceitos podem estar disfarçados até mesmo nos discursos que dizem assumir a diferença e a diversidade" (GESSER, 2009, p. 46).

Em 6 de julho de 2015 foi sancionada a Lei brasileira $\mathrm{N}^{\circ} 13.146$ a fim de instituir a Inclusão da Pessoa com Deficiência (Estatuto da Pessoa com Deficiência) e conforme o "Art. $1^{-}$[...] assegurar e a promover, em condições de igualdade, o exercício dos direitos e das liberdades fundamentais por pessoa com deficiência, visando à sua inclusão social e cidadania" (BRASIL, 2015). A garantia da igualdade, da liberdade, dos direitos e da inclusão da pessoa com deficiência na sociedade representa um avanço significativo, uma vez que o indivíduo pode viver com autonomia.

Contudo, isso não ocorre em plenitude, pois "[...] se criam situações de conflito e de atrito na sociedade, ocasionando dificuldades sociais e atitudes excludentes [...]”. (BARROS, 2015, p. 67). Tais conflitos e atritos podem ter diversas causas, no entanto, seus efeitos levam a exclusão e a desigualdade; e o preconceito surge do "não-conhecimento" em relação ao outro, que é diferente, mas não desigual. A autora ainda apresenta o caminho para resolvermos estas divergências: “A cada ação de exclusão devemos contrapor ações de inclusão [...]”, isto é, o oposto das ações excludentes encontra-se nas ações inclusivas.

Coneglian e Silva (2006, p. 6) destacam do Relatório Diretrizes para Serviços de Biblioteca para Surdos elaborado pela IFLA (2000) a afirmativa de que há barreira na comunicação com esse público e então é preciso que as bibliotecas: “[...] direcionem esforços 
O mediador e a mediação de literatura para crianças surdas

planejados e específicos ao público com surdez, justamente pela dificuldade de leitura percebida em natissurdos ou crianças que perderam a audição na primeira infância”.

Barros (2006, p. 148) destaca algumas sensações que um texto pode provocar (surpresa, amor, lágrimas, riso). Com isso a autora salienta a potencialidade que um texto, um autor, enfim, que a leitura tem em provocar reações e emoções das mais diversas, oscilando da lágrima ao riso, como tempero da vida na sala de aula e na biblioteca. Porém, um mesmo texto poderá evocar diferentes reações porque estas dependem da visão de mundo de cada criança, daquilo que vivenciou, de sua própria história. Conforme Domingues et al. (2008, p. 8) para pessoas com deficiência os processos de leitura e de escrita "[...] precisam ser ensinados e estimulados de forma diferenciadora". Assim, é necessário desenvolver e estimular a leitura e a escrita na pessoa com deficiência de maneira diversificada. Muitas vezes, suas reações surpreendem os profissionais “[...] pela sua dedicação, interesse e desenvolvimento cognitivo". (DOMINGUES et al., 2008, p. 8).

Em relação a tal aspecto, as mesmas autoras acrescentam que os atributos da leitura podem ser partilhados com pessoas com necessidades especiais, na medida em que "Com deficiência mental, física, motora, auditiva e/ou visual, estas pessoas podem ser estimuladas através de atividades de leitura e de atividades lúdicas para atingir o máximo de suas potencialidades" (DOMINGUES et al. 2008, p. 8).

No caso da criança surda, vale destacar que não se limita a falta de audição, mas ultrapassa esse aspecto com o desenvolvimento da Língua de Sinais que garante aos surdos o pertencimento a uma comunidade. Nesse sentido, Santana (2007, p. 33) afirma que "Conferir à língua de sinais o estatuto de língua não tem apenas repercussões linguísticas e cognitivas, mas também sociais. [...] a língua de sinais legitima o surdo como ‘sujeito de linguagem"”.

Assim, defendemos que a mediação da leitura é necessária para crianças surdas com o intuito de aproximá-las da leitura e da literatura. Isso por acreditar que os indivíduos podem ter seu desenvolvimento favorecido pela leitura, especialmente no que se refere à percepção de mundo de cada um, a fantasia, a descoberta.

O conceito de mediação que nos identificamos tem origem nas discussões de Almeida Júnior e Bortolin (2008, p. 77). Para os referidos autores, a mediação da leitura é: 
uma ação de interferência - realizada por um mediador que pode ser definido como uma pessoa que tem a responsabilidade de acompanhar um leitor durante a sua formação ou mesmo depois de formado (na medida em que a formação é contínua) quando em dúvida ou desencorajado, solicita uma sugestão. Ou aquele profissional que tem possibilidade de intervir nas escolhas de leitura de um determinado grupo, visando levar seus membros a se encontrarem (de preferência amorosamente) com diferentes textos.

Portanto, a mediação da leitura é uma ação em que o mediador pode seduzir e despertar o interesse pela leitura, pois ao interferir na escolha do leitor pode levá-lo aos diversos caminhos da leitura de maneira prazerosa e amorosa. Nesse sentido, Silva (2015, p. 502) destaca que

Caberá ao mediador compreender a formação de leitores como um processo constante na escola e na vida e que, portanto, deve ser generoso com aquele que inicia essa jornada, apoiando-o, incentivando a escolher suas próprias leituras sem criticá-lo e, ao mesmo tempo, oferecer possibilidade para que encontre novos textos.

Nesse trabalho a proposta é pela mediação por intermédio do livro de imagem, que segundo Camargo (1995, p. 70) “[...] são livros sem texto. As imagens é que contam a história. Os livros com pouco texto, em que o papel principal cabe à ilustração, também podem ser chamados de livros de imagem". O autor conceitua os livros de imagem pela ausência do texto/palavra escrita, ou pela pequena presença desta, pois é a ilustração que tem a função de narrar neste gênero.

Além disso, Camargo (1995, p. 70) menciona que há outras denominações para o livro de imagem, entre elas: “[...] álbum de figuras, álbum ilustrado, história muda, história sem palavras, livro de estampas, livro de figuras, livro mudo, livro sem texto, texto visual, etc."

Vale destacar que o livro de imagem não é apenas um aporte para crianças não letradas, na medida em que não possui palavras. Ao contrário, a leitura deste depende das experiências individuais, das indagações do leitor diante das imagens, e ainda pode vir a ser (devir) o início de outras leituras, de significação e ampliação da nossa consciência individual e coletiva, nossas relações pessoais e culturais.

Em Abramovich (2001, p. 26) encontramos a afirmação de que o livro de imagem se trata de “[...] narrativa apenas visual, onde toda história é contada através de desenhos ou fotos, sem nenhuma palavra". Conforme o conceito da autora são histórias sem texto escrito que utilizam diferentes recursos, desde o movimento do desenho nas páginas até o surgimento de elementos da história que além de divertir, encantam e fascinam a criança, pois contém recursos que envolvem e atraem este leitor por suas infinitas possibilidades. Para ela, a história na sua totalidade é contada por meio das imagens. A autora elenca alguns autores brasileiros e estrangeiros consagrados neste gênero, entre eles: Angela Lago, Juarez Machado, Edith 
Derdyk, Eliardo França e Monique Felix, e também o pioneirismo de Juarez Machado no livro de imagem ${ }^{1}$.

Citando Paiva (2014, p. 46) destacamos que apesar da ausência da palavra escrita, os livros de imagem têm potencial de incentivo à leitura. Para ela os "[...] livros de imagem não empregam a escrita textual para exprimir em suas páginas um caminho-guia ou um respaldo para os acontecimentos em cena, mas ainda assim podem incentivar a leitura [...]".

A este propósito, Alencar (2009, p. 29) também salienta outros efeitos que a imagem no livro infantil provoca no leitor influxos que: “[...] desenvolve a sensibilidade, aguça o gosto estético, experiencia emoções diversas suscitadas pelas imagens, bem como alimenta a alma, pois a sedução das imagens é um convite ao mergulho, ao aprofundamento, a ser feito sozinho ou com a ajuda de um mediador.

\section{Procedimentos Metodológicos}

Para executarmos a proposta inicial desta pesquisa e garantirmos a compreensão de nosso estudo, utilizamos a pesquisa descritiva, pois de acordo com Gil (2008) seu principal objetivo é descrever as características de uma população ou fenômeno bem como estabelecer relações entre as variáveis.

Considerando que os objetivos propostos foram analisar a mediação como ação de incentivo à leitura para a criança surda, bem como, caracterizar a ação de mediação estabelecendo associações entre estas e a leitura, a pesquisa descritiva foi a mais apropriada.

A natureza do estudo qualitativo justifica-se pela amostra desta pesquisa ser reduzida e pela sua abordagem que permite a busca e interpretação mais aprofundada dos dados, assim procuramos descrever a mediação, destacando sua importância e relações com a leitura, que nesse caso ocorreu por meio de um estudo de caso e para tal utilizamos a entrevista gerativa de narrativa. Segundo Muylaert et al. (2014, p. 194) "as entrevistas narrativas se caracterizam como ferramentas não estruturadas, visando a profundidade, de aspectos específicos, a partir das quais emergem histórias de vida [...]”.

\footnotetext{
${ }^{1}$ Camargo (1995) destaca que o livro Ida e Volta de Juarez Machado é considerado o primeiro livro só de imagem brasileiro.
} 
Nosso universo de pesquisa foi o Colégio Estadual do Instituto Londrinense de Educação de Surdos (ILES). Fundado em 1959, por Rosalina Lopes Franciscão, Odésio Franciscon e pelo Bispo da Diocese de Londrina D. Geraldo Fernandes. É considerada uma obra precursora, em Ensino Especial, no Norte do Estado do Paraná quanto ao atendimento de pessoas surdas. (PROJETO..., 2012). O Colégio Estadual do ILES oferece a Educação Básica, na modalidade Educação Especial para estudantes surdos, dentre as quais a Educação Infantil de 0 a 5 anos, o Ensino Fundamental do $1^{\circ}$ ao $9^{\circ}$ ano, o Ensino Médio e a Classe de Dupla Deficiência (PROJETO..., 2012).

A Biblioteca do Instituto possui um acervo de 4.380 livros didáticos e paradidáticos, periódicos, revistas diversas, gibis, materiais produzidos pelos professores e crianças (apostilas, livros de histórias), mapas, globos, maquetes, jogos didáticos (mapas em madeira), CD-ROM, cartazes do curso de LIBRAS etc.

Dentre as atividades realizadas na biblioteca podemos mencionar as pesquisas, os empréstimos de livros e materiais, assim como o uso do espaço tendo como objetivo atender às necessidades dos professores e dos estudantes a fim de incentivar o gosto pela leitura e o prazer ao estudo. O horário de atendimento ocorre de segunda à sexta-feira das $7 \mathrm{~h} 20$ às $11 \mathrm{~h} 40$ e das 13 h30 às 17h00. (PROJETO..., 2012).

O público alvo desse estudo foi composto por 2 professores do ILES que utilizam o livro de imagem nas atividades de contação de história para crianças surdas. No entanto, em virtude do número de respondentes ser ínfimo, convidamos para participar da pesquisa 3 professores de Libras e integrantes do Grupo de Estudos: Surdos em Educação, Linguística e Informação da Universidade Estadual de Londrina (GESELI/UEL), além de 3 professores do município de Ibiporã que já lecionaram ou trabalharam com crianças surdas, totalizando 8 sujeitos de pesquisa.

Para os professores do ILES foram entregues as questões impressas na escola. Para os professores da UEL elas foram enviadas para o e-mail de cada um deles e dos professores de Ibiporã, 2 receberam as questões por e-mail e 1 recebeu a questão impressa.

Portanto, a primeira etapa da pesquisa foi a elaboração da questão gerativa, a segunda etapa foi a entrega das questões, a terceira etapa foi a obtenção das respostas, a quarta etapa foi a criação das categorias e última etapa foi a análise das experiências. 
Assim, a partir das respostas obtidas, criamos seis categorias de assuntos abordados pelos sujeitos a fim de que pudéssemos comparar as diferentes experiências e estabelecer semelhanças e divergências. Estas categorias contemplaram a dificuldade ou facilidade do mediador, a experiência de mediação e as estratégias utilizadas pelos mediadores, a dificuldade ou facilidade da criança surda na percepção dos mediadores, o uso de libras, as possibilidades do livro de imagem e as atividades pós-mediação.

\section{Apresentação dos Resultados}

Os sujeitos da pesquisa foram identificados pelas letras A, B, C, D, E, F, G e H sendo que os sujeitos A e B atuam no ILES, o sujeito C é professor do Departamento de Educação da UEL e membro do GESELI, os sujeitos D e E trabalham como professor de apoio nas escolas municipais de Ibiporã, o sujeito F já atuou como professor de Libras e hoje também é professor do Departamento de Educação da UEL e membro do GESELI. O sujeito G atuou como intérprete de Libras e o sujeito H lecionou em uma escola regular de Ibiporã, onde havia uma criança surda inclusa na sua turma.

A técnica de coleta de dados foi a entrevista gerativa de narrativa que se deu pela questão gerativa de narrativa respondida pelos sujeitos A, B, C, D, E e F que trabalham ou trabalharam diretamente com as crianças surdas. Portanto, a eles apresentamos a seguinte questão:

Segundo Camargo (1995, p.70) "Livros de imagem são livros sem texto. As imagens é que contam a história. Os livros com pouco texto, em que o papel principal cabe à ilustração, também podem ser chamados de livros de imagem”. Você já fez narrativas de histórias com este gênero de livro? Quando faz utiliza libras? Gostaria que nos contasse como desenvolve essa atividade e se tem alguma dificuldade.

Os sujeitos $\mathrm{G}$ e H que não trabalharam diretamente com crianças surdas responderam a questão gerativa de narrativa com uma adaptação na parte final: Se você tivesse que realizar uma atividade para crianças surdas com este gênero de livro como faria? Gostaria que nos contasse como desenvolveria essa atividade e se teria alguma dificuldade.

A partir das respostas obtidas, criamos seis categorias de assuntos abordados pelos sujeitos, sendo: Categoria 1: Dificuldade/facilidade do mediador, Categoria 2: Experiência de mediação/estratégias, Categoria 3: Dificuldade/Facilidade da criança surda (na percepção dos 
sujeitos), Categoria 4: Uso de libras, Categoria 5: Possibilidades do livro de imagem e Categoria 6: Pós-mediação.

Assim, na Categoria 1 os sujeitos mencionaram suas dificuldades ou facilidades em relação à mediação com o livro de imagem, na Categoria 2 eles relataram sua experiência de mediação bem como as estratégias empregadas, na Categoria 3 os sujeitos evidenciaram as dificuldades/facilidades das crianças surdas assim como o protagonismo delas nas atividades, na Categoria 4, eles ressaltaram a importância da Língua de Sinais, na Categoria 5, eles comentaram as possibilidades do livro de imagem e na Categoria 6 os sujeitos citaram as possíveis atividades “pós-mediação".

\section{Categoria 1 - Dificuldade/Facilidade do Mediador}

A proposta da primeira questão gerativa de narrativa é verificar junto aos sujeitos se há dificuldade quanto ao desenvolvimento da atividade com livros de imagem. A respeito desta categoria, obtivemos os seguintes resultados: os sujeitos A e C responderam que não têm dificuldade. O sujeito A afirma que a atividade é desenvolvida semanalmente, sem qualquer dificuldade. $\mathrm{O}$ sujeito $\mathrm{C}$ comenta que não tenho dificuldade em fazer a atividade em Libras.

Os sujeitos $\mathrm{B}, \mathrm{D}, \mathrm{F}$ e $\mathrm{G}$ não fizeram referência às dificuldades, porém tanto o sujeito $\mathrm{F}$ quanto o sujeito $\mathrm{G}$ comentaram nos seus discursos que dão liberdade para criança surda e isso é fundamental para leitura.

O sujeito D já fez mediação. No caso do sujeito E que não respondeu, nas próximas respostas em seu discurso, demonstrou destreza na mediação. Assim podemos inferir que ele não tem dificuldade.

$\mathrm{O}$ sujeito $\mathrm{H}$ admite que Com certeza encontraria muitas dificuldades em desenvolver essa atividade [...]. Essa afirmação está baseada numa experiência recente quando recebeu na sua turma de $1^{\circ}$ ano do ensino regular um aluno surdo e deve que contar com a contribuição de um professor que tem fluência em Libras. Assim, a dificuldade sentida está relacionada a sua limitação no que diz respeito à Libras.

Buscando subsídios na literatura para confirmar a necessidade do preparo do mediador, nos apropriamos de Bessas e Cardoso (2011, p.146) quando afirmam que "[...] o narrador de uma história deve usar fluentemente a língua de sinais: os sinais, o espaço, a expressão corporal e facial, a sintaxe e todos os elementos que compõem a língua de sinais”. 


\section{Categoria 2 - Experiência de Mediação/Estratégias}

Nesta categoria, obtivemos as experiências dos sujeitos A, B, D, E, F e H, sendo que o sujeito $C$ não nos relatou experiências e o sujeito $G$ afirmou que não teve.

Pudemos observar que os sujeitos A e B dialogam com o aluno durante a mediação com livros de imagem. Conforme o sujeito A As informações explícitas e implícitas comunicadas neste tipo de texto são trabalhadas através de exposição dialogada [...]. Da mesma forma, nas atividades de mediação o sujeito B comenta: [...] observamos as ilustrações, dialogamos (Libras) [...] e observamos os interesses dos mesmos.

Os sujeitos D, E e G também valorizam a observação dos livros de imagem, sendo que o sujeito D ressaltou a importância do aluno ter contato direto com os livros: [...] na narrativa de história com livros de imagem, é importante que o aluno primeiramente manuseie-o, para conhecê-lo, sinalizando os personagens e os elementos que compõe o cenário, posteriormente conta a história sinalizando e mostrando as imagens para facilitar a compreensão.

O sujeito E por sua vez comentou que em relação ao livro: [...] primeiro deixo o aluno observá-lo. E assim, ele faz sinais das figuras que conhece, analisa tamanho, cor, onde se passa, como estão trajados as personagens, dá para explorar muitas informações. Vale destacar que o sujeito E realiza a mediação individualmente, pois há apenas um aluno surdo na escola.

O sujeito G, argumentou que se fosse realizar a atividade também preconizaria a leitura individual e livre: [...] deixaria que elas fizessem a leitura sozinhas, folheando página por página livremente sem propor nada [...] para não criar expectativas ou ansiedade.

Quanto às mediações do sujeito F ele comentou: Primeiro costumava mostrar os livros com as imagens e perguntava o que elas queriam dizer. No decorrer da atividade, as crianças iam mergulhando na história contada por elas mesmas. Cada criança podia criar sua própria história olhando as imagens do livro. Notamos aqui a liberdade que o gênero proporciona com a criação de diferentes histórias.

O sujeito F também mencionou que se apropriava da biblioteca e da literatura, fato que facilita a mediação, pois aproxima as crianças do espaço de leitura e dos livros, cria vínculos e possibilita o uso dos diferentes gêneros, como o livro de imagem. 
Quanto ao sujeito $\mathrm{H}$ nas suas experiências contava com o trabalho da professora de apoio (intérprete): quando contava histórias [...] apenas com imagens a auxiliar com seus conhecimentos conseguia fazer com que o aluno entendesse a história.

\section{Categoria 3 - Dificuldades/Facilidades da Criança Surda (na percepção dos sujeitos)}

Acerca desta categoria os sujeitos A, B e D não comentaram a dificuldade ou facilidade das crianças surdas em relação à mediação, já os sujeitos $\mathrm{C}, \mathrm{E}, \mathrm{F}, \mathrm{G}$ e H fizeram referências a estes aspectos.

$\mathrm{O}$ sujeito $\mathrm{C}$ mencionou que para crianças surdas que conhecem e utilizam a Língua Brasileira de Sinais, a proposta de apresentação do livro de imagens se assemelha à da proposta para crianças ouvintes. Apesar disso, a criança surda necessita mais da experiência visual e os livros de imagem tendem a favorecê-la.

No caso do sujeito E destacou que muitas vezes a criança surda questiona a interpretação que ele, adulto, faz. Essa liberdade é importante porque se o mediador souber lidar com a opinião da criança, ela se sentirá valorizada e uma participante ativa da mediação. Assim, ele comentou: A criança surda imagina um contexto que muitas vezes não percebo, pois [...] é muito atento e detalhista, assim como todo surdo... é a partir da imagem do mundo que ela busca se comunicar. Depois vou [...] contando a minha versão da história... às vezes ela não aceita e concordo muitas vezes com o que ela fala... Aqui pudemos notar que o mediador valoriza a participação e o protagonismo da criança surda.

$\mathrm{O}$ sujeito $\mathrm{F}$ ressaltou que as crianças surdas por encontrarem dificuldades na leitura devido ao entendimento do significado das palavras dentro do contexto, os surdos não encontram muito estímulo para lerem. [...] O difícil para as crianças surdas era passar tudo para o papel a história que foi contada em Libras, pois elas possuem dificuldades com as palavras, tanto que algumas preferem desenhar a escrever. Ressaltamos a preferência pelo desenho baseada no seguinte comentário do sujeito G: as crianças surdas são muito visuais [...] elas extraem muito das imagens. O sujeito $\mathrm{H}$ enfatizou que é direito da criança surda a presença de um intérprete de Libras na escola. Portanto, as políticas de inclusão devem sair do papel e se transformar em realidade. 
Em relação ao protagonismo, Bessas e Cardoso (2011, p.145) defendem que as crianças surdas, folheiem e explorem os livros de maneira independente. Para isso, será necessário organizar espaços próprios para leitura seja na biblioteca ou na sala de aula a fim de que tenham o livro em mãos por um momento ou selecione algum para o empréstimo.

\section{Categoria 4 - Uso de Libras}

Nesta categoria, podemos afirmar que os sujeitos A, B, C, D, E e F utilizam a Libras na mediação com livros de imagem. O sujeito $\mathrm{G}$ também utilizaria se fosse desenvolver a atividade e o sujeito $\mathrm{H}$ precisaria do apoio da intérprete, pois possui um curso básico em Libras.

Dessa forma, quando questionados sobre a utilização de Libras, o sujeito A afirma que utilizou. Igualmente o sujeito B respondeu: dialogamos (Libras) [...] criamos uma história em Libras coerente com as ilustrações. Também enfatizou que a língua natural do surdo é a Libras.

A esse respeito, Gesser (2009, p. 76) nos diz que “[...] o surdo pode e desenvolve suas habilidades cognitivas e linguísticas [...] ao lhe ser assegurado o uso da língua de sinais [...]. Não é a surdez que compromete o desenvolvimento do surdo, e sim a falta de acesso a uma língua”.

Portanto, é possível deduzir que a surdez não limita a cognição do surdo, mas a ausência de uma língua sim. Aliás, segundo Erting (1978 apud FREEMAN, 1999, p. 253) “[...] a presença de um único surdo adulto, que use sinais, pode aumentar a capacidade de comunicação da criança surda".

O sujeito $\mathrm{C}$ destacou a importância do domínio de Libras na mediação: $O$ mediador precisa, para conduzir a atividade com crianças surdas, ter fluência em Língua de Sinais, de modo que possa ir dando as pistas para as crianças e respondendo as devolutivas das mesmas, conforme vão passando as páginas.

O sujeito D salientou que o livro de imagem contribui para aquisição de Libras: $A$ imagem na narrativa de histórias para o indivíduo Surdo na aquisição de sua língua é de extrema importância, pois é através do visual que ele compreende e interage com o mundo em sua volta. A esse respeito Skliar (2012, p. 28) afirma que "A surdez é uma experiência visual, 
[...] e isso significa que todos os mecanismos de processamento da informação, e todas as formas de compreender o universo em seu entorno, se constroem como experiência visual".

O sujeito E comentou que o aluno ao observar o livro de imagem [...] faz sinais da figura que conhece. Inferimos que este momento da mediação é significativo, pois permite à criança estabelecer relações entre a imagem e a sua cultura, sua língua na medida em que sinaliza em Libras, as imagens conhecidas.

O sujeito F destacou que Era uma atividade bastante prazerosa, pois a Libras permite ir além da imaginação. Notamos que o livro e a língua utilizados estimulam o imaginário infantil. O sujeito ainda esclarece que a Língua Portuguesa é a segunda língua do Surdo e a LIBRAS (Língua Brasileira de Sinais) é a primeira.

O sujeito G explicou que Quando vamos fazer perguntas em Libras do tipo "o que você fez no final de semana? "; para que a criança entenda e responda precisamos mudar a estrutura para uma afirmativa aberta como "no final de semana você brincou, passeou,... o que mais?" Daí a importância de explorar esses elementos a partir dos livros de imagem. Portanto, concluímos que tanto a Libras quanto o livro de imagem possibilitam à criança surda acrescentar informações conforme o contexto.

$\mathrm{O}$ sujeito $\mathrm{H}$ ressaltou que [...] para se contar uma história com livros [...] só com imagens para crianças surdas requer domínio da Língua Brasileira de Sinais (Libras). Enfatizou que [...] apesar de saber que contaria com uma intérprete auxiliar fiquei preocupada e tratei de começar um Curso Básico de Libras que foi muito bom, mas era muito pouco, precisava avançar mais e mais.

Dessa forma, não somente o sujeito E deveria buscar o aprendizado de Libras, mas os demais profissionais da escola, pois é papel da escola tornar os "[...] professores proficientes na língua de sinais; que permita a alfabetização na língua primeira e natural dos surdos...” (GESSER, 2009, p. 58).

Esta falta de profissionais fluentes em Libras evidencia que na realidade, “[...] a escola [...] não está aparelhada para lidar com a diferença, com o novo, com o inusitado. Como é repetitiva, não sabe transformar e criar segundo as necessidades que surgem, não se projeta para o futuro" (AGUIAR, 2006, p. 240).

Neste contexto, "[...] o benefício potencial para uma criança que frequente uma préescola regular para crianças ouvintes vai depender da preparação do quadro de pessoal da 
escola, de modo que tanto eles como as crianças ouvintes possam aprender a se comunicar por sinais" (FREEMAN, 1999, p. 253). Dessa maneira, o desafio do professor de surdos é propiciar o encontro com uma diversidade de textos imensurável. Entendemos que o livro de imagem contribui para o "maravilhamento" da criança surda em relação a percepção do mundo.

\section{Categoria 5 - Possibilidades do Livro de Imagem}

Os sujeitos A, B, C, D, E e F comentaram a importância ou as possibilidades do livro de imagem. Os sujeitos $\mathrm{G}$ e $\mathrm{H}$ não mencionaram esta abordagem.

De acordo com o sujeito A, as informações deste tipo de texto [...] possibilita ao grupo opinar sobre o mesmo, expor criativa e inventivamente um ponto de vista. Assim, os alunos dialogam e emitem opiniões, além de posicionar-se criativamente a respeito da narrativa. Segundo Paiva (2014, p. 56) desvendar a imagem por meio da leitura é "[...] um desafio instigante que valoriza a observação e as opiniões dos alunos, a bagagem cultural do grupo e a capacidade associativa/interpretativa das crianças". O sujeito A conclui: [...] Sem dúvida, um trabalho essencial para as crianças/jovens surdos.

O sujeito B conta que aproveitava [...] o momento para que os alunos relatassem vivências pessoais [...]. Desse modo, a leitura do livro de imagem permite o relato das experiências de cada aluno. Cademartori ([20??], p. 4) afirma que com o livro de imagem o leitor "[...] olha, interpreta, avalia, e descobre sentidos, tanto na leitura individual quanto na partilha da experiência com colegas e professores".

Além disso, segundo o sujeito B: A narrativa de histórias utilizando ilustrações pode propiciar ao surdo oportunidades de desenvolvimento na Libras e em Português (escrito).

Portanto, produzir textos a partir da narrativa do livro de imagem possibilita à criança surda o desenvolvimento da leitura e da escrita em Língua Portuguesa, além de Libras. Nesse sentido vale destacar que "[...] as experiências escolares [...] privilegiem não apenas a língua de sinais, mas também os aspectos discursivos da escrita, já que estes são fundamentais para que o surdo se constitua como sujeito leitor e escritor [...]" (GUARINELLO, 2007, p. 58).

Para o sujeito C Os livros de imagem são ótimos recursos para a contação de histórias, pois, permite ao público-alvo escolher o ritmo da narração segundo o que vê e percebe das 
imagens e a sequência proposta pelo autor [... é é muito rica e produtiva a atividade de contação de histórias com esse suporte.

O sujeito D comentou que [...] esse tipo de recurso pedagógico (livro de imagem) é muito válido para o trabalho com o aluno Surdo, principalmente aqueles que estão na aquisição da Língua de Sinais.

O sujeito E notou que com livros de imagem a criança surda participa mais: Com este material há um envolvimento maior por parte dele durante a contação. Este envolvimento evidencia que o livro de imagem é um dispositivo eficaz a ser utilizado na mediação de leitura.

O sujeito E lembra que na escola há poucos livros do gênero e [...] seria de muita valia, pois faz a criança imaginar, contar ou escrever a sua própria história a partir de uma mesma imagem teríamos diferentes versões o que nos remete as experiências vividas pelo autor (a)...

Cademartori ([20??], p. 4) explica que um mesmo livro de imagem pode gerar diferentes histórias porque depende da "[...] percepção e a subjetividade de cada criança, segundo as vivências que tenha e as projeções que puder fazer, [...] legitimadas pelo direito do leitor de atribuir sentidos ao que lê".

$\mathrm{Na}$ concepção do sujeito $\mathrm{F}$ o livro de imagem [...] é muito bom para a leitura com crianças surdas, pois é através das imagens que flui a imaginação visual.

\section{Categoria 6 - Pós-Mediação}

Em se tratando desta categoria, os sujeitos A, B, F e G destacaram as atividades que realizam após a mediação com livros de imagem. No discurso dos sujeitos C, D, E e H não houve menção a pós-mediação.

O sujeito A salientou que [...] após um trabalho de leitura há oportunidade de uma atividade complementar, de preferência concreta como: realização de um teatro elou dramatização, [...] construção de objetos com reálias/sucata etc.

O sujeito B comentou que As crianças surdas criam [...] uma história em Libras coerente com as ilustrações. Utilizam a [...] história (criada pelo grupo) para realizar a produção textual em Língua Portuguesa. 
O sujeito F evidenciou que após a contação da história elas desenhavam ou escreviam a história (dependendo do nível de escolaridade).

Em um momento posterior a leitura $o$ sujeito G [...] pediria que a criança me contasse a história e a partir daí exploraria a leitura perguntando detalhes que a fizessem desenvolver melhor a compreensão, com os 'o quê', 'por quê', 'como', 'onde’?

Estas atividades elencadas também valorizam a participação das crianças surdas, sendo que além de desenhar, como abordou o sujeito $\mathrm{F}$, elas poderiam criar seus próprios livros de imagem e compartilhar com a turma.

Segundo Paiva (2014, p. 57) “[...] o professor pode estimular a prática de contação que amplia versões para um mesmo texto visual [...] igualmente pode incentivar, pela faixa etária, a produção de desenhos ou textos a partir das leituras autônomas ou mediadas [...]”.

Assim sendo, o mediador pode incentivar as crianças a contar e compartilhar com a turma a sua versão pessoal da história, isto é, a interpretação que fez da narrativa, e partindo dela, elaborar desenhos e textos, que podem ser produzidos também após a mediação.

\section{Considerações finais}

Nossa pesquisa nos permitiu constatar que a escola especializada para surdos possui em sua biblioteca com um rico acervo de livros de imagem que são utilizados nos momentos de mediação da leitura. Esta diversidade de títulos possibilita aos mediadores "seduzir" os leitores com as diferentes narrativas e ampliar as experiências de leitura.

Entretanto, os relatos mostram que uma escola regular que atende um aluno surdo não está preparada para lidar com a surdez, pois além de possuir um número pequeno de livros de imagem, não conta com professores fluentes em Libras, aliás, os poucos que dominam a Língua de Sinais não têm os recursos necessários para o aprendizado e desenvolvimento da criança surda.

De fato, a escola regular não está preparada para conviver com as diferenças e assim transformar a realidade conforme as necessidades das pessoas. Nesse sentido, uma dificuldade elencada por um dos mediadores foi a ausência da biblioteca e poderíamos acrescentar, do bibliotecário. Este último também precisa estar preparado para atender os surdos sendo que 
poderia trabalhar em conjunto com o professor mediador de leitura ou os intérpretes trocando experiências e conhecimento, além de buscar o aprendizado e o aprimoramento em Libras.

$\mathrm{Na}$ literatura encontramos a afirmação de que o convívio com um surdo adulto que utilize a Língua de Sinais pode favorecer a criança surda, no que se refere a sua comunicação. Por isso, inferimos que quanto maior o número de mediadores com fluência em Libras, maior será a quantidade de serviços oferecidos aos surdos, por exemplo, em uma biblioteca.

$\mathrm{Na}$ biblioteca escolar, pública ou em qualquer outro gênero, é direito do surdo a acessibilidade plena e isto inclui desde a comunicação em sua língua primária até apropriação das atividades desenvolvidas, como a mediação da leitura, do uso dos livros, do contato com a literatura infantil de maneira satisfatória e inclusiva.

Em se tratando de inclusão, sabemos que as leis são essenciais porque garantem e efetivam os direitos dos indivíduos, no entanto, elas não bastam para eliminar os preconceitos existentes e a falta de acessibilidade. Isso vai depender da mudança de nossas atitudes e de ações pensadas e desenvolvidas para todas as pessoas sem discriminação.

Embora o livro de imagem carregue o estigma da falta de palavras e consequentemente falta de leitura de texto, compreendemos que este gênero é uma forma de leitura ampla e valiosa. Nas palavras de Gondim, Cunha e Dias (2006, p. 17) "A leitura de imagens é fundamental e imprescindível. É a capacidade de formar e de ler imagens, de imaginar que vai permitir a leitura conotativa e criadora [...], a leitura das entrelinhas". Assim, os livros de imagem se configuram como possibilidade de leitura da literatura infantil, pois além de permitir o contato com obras esteticamente elaboradas que implica no contato com o belo e o prazer.

A experiência de apreciação da ilustração permite também a criança surda criar mil e uma histórias, estimulando o imaginário infantil, algo fundamental nesta fase da vida, para o crescimento pessoal que pode ser favorecido com a ação do mediador de leitura.

O mediador não pode ignorar a importância da mediação da leitura principalmente no que se refere a sua responsabilidade na formação dos leitores, assim como a ética para com o outro, a ética em relação à criança surda que comece com a apropriação de recursos que estimulem ainda mais suas habilidades.

A esse respeito, destacamos a iniciativa de um sujeito-mediador quando mencionou que alterou o momento da mediação, ainda que realizada individualmente, mas buscando os dispositivos mais adequados para a criança surda como o livro de imagem associado a Libras, 
bem como a mediação realizada de forma ampla, ao permitir que a criança surda exponha a sua visão da narrativa, sendo que esta muitas vezes prevalece, não havendo imposição ou correção em relação à sua compreensão.

Entendemos ainda que a ação do intérprete se configura em uma mediação, e como toda mediação não há neutralidade. Daí a importância da ética desse e dos demais profissionais.

Além disso, já mencionamos a importância de o mediador dominar a Língua de Sinais, língua primária com a qual o surdo conhece o mundo e pode vivenciar as maravilhas do universo da literatura infantil.

Também, pudemos perceber a atitude ética do sujeito-mediador que buscou conhecimento em Libras, ainda que na modalidade básica, e consequentemente em relação à surdez. É prioritariamente pela "experiência visual" que o surdo conhece o mundo e nesse sentido, o livro de imagem é importante porque se constitui em uma experiência do olhar.

Assim podemos concluir que a mediação com livros de imagem é uma ação imprescindível de incentivo à leitura para crianças surdas, portanto pesquisar essa temática é uma tarefa fundamental e urgente.

\section{Referências}

ABRAMOVICH, F. Literatura infantil: gostosuras e bobices. 5. ed. São Paulo: Scipione, 2001.

AGUIAR, V. T. Leitura literária e escola. In: EVANGELISTA, A. A. M.; BRANDÃO, H. M. B.; MACHADO, M. Z. V. (Org.). A escolarização da leitura literária: o jogo do livro infantil e juvenil. Belo Horizonte: Autêntica, 2006. p. 235-256.

ALENCAR, J. As ilustrações na literatura infantil: da alma das imagens à alma dos leitores. In: GÓES, L. P.; ALENCAR; J. (Org.). Alma da imagem: a ilustração nos livros para crianças e jovens na palavra de seus criadores. São Paulo: Paulus, 2009. p. 26-34.

ALMEIDA JÚNIOR, O. F.; BORTOLIN, S. Mediação da informação e da leitura. In: SILVA, T. E. (Org.). Interdisciplinaridade e transversalidade em ciência da informação. Recife: Néctar, 2008. p. 67-85.

BARROS, M. H. T. C. De leitura, classes especiais e bibliotecas escolares. In: BORTOLIN, S.; SILVA, R. J. Leitura: mediação e mediador. São Paulo: FA, 2006. p. 147155. 
Atividades culturais e a inclusão na biblioteca pública. In: SILVA, J. F. M. (Org.). A biblioteca pública em contexto: cultural, econômico, social e tecnológico. Brasília: Thesaurus, 2015. p. 67-82.

BESSAS, A. M. P.; CARDOSO, H. C. S. O uso da imagem não-verbal no processo de contação de histórias para crianças surdas. Perquirere - Revista do Núcleo Interdisciplinar de Pesquisa e Extensão, Patos de Minas, v. 1, n. 8, p. 139-151, jul. 2011. Disponível em: $<$ http://perquirere.unipam.edu.br/documents/23456/50270/o_uso_da_imagem_nao_verbal_no _processo.pdf>. Acesso em: $10 \mathrm{dez} .2015$.

BRASIL. Presidência da República. Casa Civil. Subchefia para Assuntos Jurídicos. Lei no 13.146, de 6 de julho de 2015. Institui a Lei Brasileira de Inclusão da Pessoa com Deficiência. Diário Oficial da União, Brasília, 07 jul. 2015. Disponível em: $<$ http://www.planalto.gov.br/ccivil_03/_Ato2015-2018/2015/Lei/L13146.htm>. Acesso em: 10 nov. 2015.

BORTOLIN, S. Mediação oral da literatura: a voz dos bibliotecários lendo ou narrando. 2010. 232 f. Tese (Doutorado em Ciência da Informação) - Faculdade de Filosofia e Ciências, Universidade Estadual Paulista, Marília, 2010. Disponível em:

<https://www.marilia.unesp.br/Home/Pos-

Graduacao/CienciadaInformacao/Dissertacoes/bortolin_s_do_mar.pdf $>$. Acesso em: 22 jan. 2016.

CADEMARTORI, L. Para pensar o livro de imagens. Belo Horizonte: Autêntica, [20??]. Disponível em:

<http://grupoautentica.com.br/download/roteiros/roteiro_livro_de_imagens.pdf $>$. Acesso em: 27 jan. 2016.

CAMARGO, Luís. Ilustração do livro infantil. Belo Horizonte: Editora Lê, 1995.

CONEGLIAN, A. L. O.; SILVA, H. C. Biblioteca inclusiva: perspectivas internacionais para o atendimento a usuários com surdez. In: ENCONTRO NACIONAL DE PESQUISA EM CIÊNCIA DA INFORMAÇÃO, 7., 2006, Marília. Anais eletrônicos... Marília: ANCIB, 2006. Disponível em:

〈http://enancib.ibict.br/index.php/enancib/viienancib/paper/viewFile/2485/1616>. Acesso em: 20 ago. 2015.

DOMINGUES, F. et al. O ato de ler para alunos da educação especial. Extensio: Revista Eletrônica de Extensão, Florianópolis, v. 3, n. 4, p. 1-10, ago. 2008. Disponível em: <https://periodicos.ufsc.br/index.php/extensio/article/view/5569>. Acesso em: 30 jul. 2015.

FREEMAN, R. D. et al. Seu filho não escuta?: um guia para todos que lidam com crianças surdas. Brasília: Coordenadoria Nacional para Integração da Pessoa Portadora de Deficiência, 1999.

GESSER, A. LIBRAS? Que língua é essa?: crenças e preconceitos em torno da língua de sinais e da realidade surda. São Paulo: Parábola, 2009.

GIL, A. C. Métodos e técnicas de pesquisa social. 6. ed. São Paulo: Atlas, 2008. 
GONDIM, M. M. R.; CUNHA, M. A. A.; DIAS, S. A. P. W. Linguagens e códigos. In: MENEZES, M. B.; RAMOS, W. M. (Org.). Livro de estudo: módulo IV. Brasília: MEC, 2006. Disponível em:

<http://portaldoprofessor.mec.gov.br/storage/materiais/0000012792.pdf > . Acesso em: 29 jan. 2016.

GUARINELLO, A. C. O papel do outro na escrita de sujeitos surdos. São Paulo: Plexus, 2007.

MUYLAERT, C. J. et al. Entrevistas narrativas: um importante recurso em pesquisa qualitativa. Revista da Escola de Enfermagem da USP, v. 48, p. 193-199, dez. 2014. Disponível em: <http://www.revistas.usp.br/reeusp/article/view/103125>. Acesso em: 08 fev. 2016.

PAIVA, A. P. Livros de imagem: como aproveitar a atratividade e desenvolver o potencial destas obras na sala de aula com atividades literárias. In: LITERATURA fora da caixa. Brasília: Ministério da Educação, Secretaria de Educação Básica, 2014. v. 3. p.43-58.

PROJETO Político Pedagógico. Londrina: Colégio Estadual do Instituto Londrinense de Educação de Surdos, 2012. Disponível em:

$<$ http://www.ldainstitutosurdos.seed.pr.gov.br/modules/conteudo/conteudo.php?conteudo=10 >. Acesso em: 24 ago. 2015.

SANTANA, A. P. Surdez e linguagem: aspectos e implicações neurolingüísticas. São Paulo: Plexus, 2007.

SILVA, R. J. Formar leitores na escola: o projeto pedagógico, a biblioteca escolar e a mediação. Informação \& Informação, Londrina, v. 20, n. 3, p. 487-506, set./dez. 2015. Disponível em:

<http://www.uel.br/revistas/wrevojs246/index.php/informacao/article/view/15390/17677>. Acesso em: 01 jun. 2016.

SKLIAR, C. Os estudos surdos em educação: problematizando a normalidade. In:

(Org.). A surdez: um olhar sobre as diferenças. Porto Alegre: Mediação, 2012. p.7-32. 